\title{
EXECUTIVOS SOB INTERVENÇÃO: organização e controle do trabalho sob a lógica da financeirização
}

\section{EXECUTIVES UNDER INTERVENTION: work organization and control under the financialization logic}

\author{
Patrícia Saltorato* \\ Tiago Fonseca Albuquerque Cavalcanti Sigahi** \\ Geraldo Tessarini Junior $^{* * *}$
}

\begin{abstract}
Resumo
O presente artigo explora a organização do trabalho com foco na gestão do desempenho e nos mecanismos de controle em uma credenciadora de cartões de crédito, após sua aquisição por uma grande instituição financeira nacional e a subsequente adoção de uma gestão financeirizada para sua condução. Para tanto, foi realizado um estudo de caso que, por meio de entrevistas, questionários, observação participante e consulta a fontes documentais oficiais, públicas e privadas, da empresa, identificou tanto alterações pragmáticas como outras de natureza simbólica na organização do trabalho da credenciadora. Dentre os resultados, tem-se o fechamento do seu capital na Bovespa; a criação da área Telecontrole-Intervenção; a intensificação do controle e jornada do trabalho; o aumento da flexibilidade e da autonomia do trabalhador; alterações em seus esquemas remuneratórios, dentre outras de natureza simbólica. Considerando, ainda, essas últimas, destaca-se as premissas inscritas na Gestão Baseada em Valor (GBV), como o foco no aumento do Economic Value Added (EVA), um dos indicadores financeiros mais emblemáticos da financeirização da gestão que, no caso estudado, mostrou que a reprodução de práticas ligadas a essa dinâmica contribuiu positivamente para seu incremento na credenciadora, ainda que a distribuição dos resultados financeiros entre os trabalhadores venha diminuindo em prol de sua distribuição entre os acionistas da instituição financeira. Uma das contribuições mais relevantes da pesquisa recai sobre o levantamento de dispositivos que contribuem para uma crescente individualização, competição e precarização do trabalho, experimentada por trabalhadores, agora, ameaçados de entrar em intervenção.
\end{abstract}

Palavras-chave: Organização do trabalho. Controle. Gestão do desempenho. Financeirização.

\begin{abstract}
This paper explores the work organization focusing on its performance and control management mechanisms in a credit card credential firm after its acquisition by a large national financial institution and subsequent adoption of a financialized approach towards its management. In order to do so, a case study was conducted, which through interviews, questionnaires, participant observation and a documentary research over official and private company financial data, thus, identifying both pragmatic and symbolic changes in the work organization after its acquisition. Amongst the results, there is the exit from Bovespa, the creation of the Telecontrol-Intervention area; the intensification of control and working hours; the increased flexibility and worker autonomy; alterations in their remuneration schemes, among others of symbolic nature. Yet, considering this latter, the adoption of practices based on the Value Based Management (VBM) premises, as the focus on the Economic Value Added (EVA), one of the most emblematic financial indicators of management financialization, shows in the studied case, that the reproduction of its practices had contribute positively to its increase in the firm, even though its financial results distribution among workers has decreased in favor of increased distribution among the financial institution's shareholders. One of the research's most relevant contributions calls the attention towards the increased individualization, competition, and precariousness experienced by workers now threatened to face interventions.

Keywords: Work organization. Work control. Performance management. Financialization.

\footnotetext{
* Professora do Programa de Pós-Graduação em Engenharia de Produção (PPGEPS - UFSCar/Sorocaba) e pesquisadora do Núcleo de Sociologia Econômica e das Finanças (NESEFI - UFSCar/São Carlos). E-mail: patrisal@ dep.ufscar.br

** Doutorando em Engenharia de Produção - USP/São Paulo. E-mail: tiagosigahi@usp.br

*** Mestrando em Engenharia de Produção - UFSCar/Sorocaba. E-mail: geraldo.tessarini@gmail.com
} 


\section{Introdução}

A partir do final da década de 1990, a ascensão de uma lógica financeira e de seu corolário, o da criação de valor ao acionista, tem ganhado espaço junto à gestão das empresas nacionais (GRÜN, 2003; BARRETO, 2011; MUNDO NETO, 2011; SALTORATO et al., 2014; MATSUDA; DONADONE, 2015) e internacionais (FLIGSTEIN, 1990; USEEM, 1993; FROUD et al., 2000, 2005, 2006; POWELL, 2001; ANDERSSON et al., 2008; EZZAMEL; WILLMOTT; WORTHINGTON, 2008; LEE; YIN, 2012; COOPER; EZZAMEL, 2013). O processo através do qual tal lógica financeira passa a influenciar as práticas de gestão tem sido referenciado na literatura por financeirização da produção (DIAS; ZILBOVICIUS, 2006; FANTTI, 2013); financeirização da gestão (SALTORATO; BENATTI, 2017) ou, de forma mais abrangente, financeirização (GRÜN, 1999; MORAES, 2017).

Essa dinâmica propiciou a ascensão de atores do espaço das finanças (investidores institucionais, analistas de mercado, gerentes de fundos de investimentos, economistas/ financistas, etc.) que passaram a reproduzir no espaço industrial/comercial narrativas, discursos, práticas e métricas de desempenho egressos do espaço financeiro, legitimando um novo modo de ver e agir sobre as empresas.

Segundo Van der Zwan (2014), o processo de financeirização, ou o aumento da dominância de atores financeiros (e de sua lógica financeira), pode ser percebido segundo três focos de análise distintos. O primeiro deles destaca um novo regime de acumulação liderado pelas finanças, que prioriza a valorização do capital via mercado financeiro, em detrimento de sua valorização via investimentos na esfera produtiva como forma de obtenção de riqueza (ARRIGHI, 1994; BRAGA, 1997; BOYER, 2005; CHESNAIS, 2005; EPSTEIN, 2005; THOMPSON, 2013). Uma segunda abordagem analisa a financeirização do ponto de vista organizacional, considerando suas consequências para a organização do trabalho e da produção e as respectivas tomadas de decisão de investimentos/desinvestimentos associadas a elas (FLIGSTEIN, 1990; LAZONICK; O'SULLIVAN, 2000; FROUD et al., 2006; DAVIS, 2009; MUELLERLEILE, 2009; WIDMER, 2011; SALTORATO; BENATTI, 2017; MORAES, 2017). Uma terceira abordagem dessa dinâmica foca na análise do indivíduo, considerando sua influência na vida cotidiana dos indivíduos, ou por meio da inclusão financeira da população, (MONTGOMERIE, 2006; ERTURK et al., 2007, 2008; SALTORATO et al., 2014), ou da proliferação das Ligas de Mercado Financeiro entre os alunos de Engenharia de Produção (SIGAHI; SALTORATO, 2017). Neste, o foco do processo de financeirização recairá sobre a segunda abordagem, ou seja, na análise organizacional, sendo seu objetivo explorar a organização (e o controle) do trabalho em uma empresa não financeira cuja gestão financeirizada se tornou agressivamente baseada em resultados voltados para a criação de valor ao acionista, após sua aquisição por uma instituição financeira. 


\section{Financeirização e organização do trabalho}

A dinâmica da financeirização tem assumido variadas formas e sentidos através dos quais ela se processa no espaço organizacional, seja por meio da estrutura de propriedade adotada, da composição de seu conselho de administração ou do poder de influência dos investidores institucionais. Dentre os vários mecanismos que podem ser atribuídos ao contexto de uma organização do trabalho voltada para a financeirização, tem-se uma amálgama combinando medidas pragmáticas como: o emprego de engenharia financeira; estratégias de crescimento baseadas em fusões e aquisições; terceirização da produção; abolição de medidas anti-takeover (uma vez que o sobrepreço das ações no caso de uma tomada de controle valorizaria os ganhos dos investidores); o emprego de métricas financeiras para avaliar a contribuição de cada divisão ao resultado da empresa; assim como medidas de natureza simbólica, como a difusão da cultura de curto-prazismo, o privilégio da liquidez; a ressignificação do conceito de eficiência da empresa, agora amplamente associado ao valor de suas ações; a subordinação da lógica financeira à lógica das finanças, dentre outros (SALTORATO; BENATTI, 2018).

Muitos estudos nacionais e internacionais têm demonstrado que a ascensão de tal lógica de cunho financista vem se sobrepondo à lógica produtiva junto à gestão das empresas, a partir da década de 1980, nos países desenvolvidos, e a partir do final da década de 1990 e início dos anos 2000, no Brasil (GRÜN, 1999; DIAS; ZILBOVICIUS, 2006; DIEGUEZ, 2009; MUNDO NETO, 2011; FANTTI, 2013; RACHID; RICCI; SALTORATO, 2017).

A crise de lucratividade das grandes empresas dos anos 1970 somada à adoção de políticas neoliberais a partir dos anos 1980, à desregulamentação financeira dos anos 1990 e às privatizações empreendidas nos países anglo-saxões, que desembarcaram no Brasil no fim do século XX, teriam, juntamente ao surgimento e difusão de novas tecnologias de informação, ampliado a mobilidade dos fluxos de capitais entre diferentes mercados nacionais, acentuando tal processo. A ascensão de tal lógica não significaria, tão somente, uma redução do volume de investimentos na indústria e o respectivo aumento desses no mercado financeiro, mas também uma dominação/subordinação da esfera produtiva à lógica financista, por meio da reprodução na esfera produtiva de narrativas, discursos, práticas e métricas de desempenho, egressos do espaço financeiro (DIAS; ZILBOVICIUS, 2006), equiparando as relações organizacionais internas às relações de mercado, transformando as estratégias organizacionais. Um exemplo da colonização financeira sofrida pela esfera produtiva pode ser percebido no emprego da métrica, Retorno sobre os Ativos (ROA), obtida a partir da razão entre lucro líquido/valor dos ativos, que passou a mensurar a rentabilidade (ou o desempenho financeiro) da esfera produtiva. Segundo Fligstein (2005), executivos orientados "financistamente" (para a criação de valor ao acionista) perceberam que a retirada dos ativos dos balanços poderia melhorar o desempenho financeiro das firmas e, para isso, encontraram vários meios de fazê-lo. Uma destas formas passou a incluir a terceirização de máquinas, escritórios ou fábricas, de maneira 
que tais ativos deixassem de constar no balanço ainda que a decisão pela terceirização possa incorrer na geração de custos.

Nesse sentido, a ascensão de tal lógica teria impulsionado os processos de internacionalização e terceirização da produção, a "manufatura por contrato" ou, ainda, a "servitização da manufatura", originando as "fábricas que não fabricam", por um lado e, por outro, as "empresas sem marcas" (chinesas, taiwanesas, etc.) que, por exemplo, atuam na cadeia de eletroeletrônicos, fabricando para as grandes marcas americanas e europeias. A lógica financista antagonizaria, assim, com a produtiva ao pressupor a geração de custos (advindos da terceirização da gestão da produção, em todos os seus aspectos, como a gestão da qualidade, da cadeia de suprimentos, pós-venda, etc.) caso os mesmos possam representar a melhora de índices de desempenho financeiro da empresa. Fligstein (2005) ainda aponta outros meios através dos quais a retirada dos ativos do balanço pode acontecer por meio do emprego de engenharia financeira.

Figura icônica quando se trata do emprego de engenharia financeira, Andy Fastow, um dos magos/arquitetos da manipulação financeira empreendida pela Enron ${ }^{1}$, empunhava, no Financial Times Alphaville Summit, em 2015, seu prêmio de melhor CFO de 2000 em uma das mãos e sua identificação carcerária na outra, alegando que as mesmas práticas que lhe renderam seu prêmio, lhe renderam depois sua condenação, destacando a ambiguidade contábil das novas regras do jogo da financeirização, impelindo a valorização de ações por meio de práticas contábeis questionáveis (SHEPPARD; HUME, 2015).

No contexto brasileiro são emblemáticos os casos de emprego de engenharia financeira da Sadia e da Aracruz por meio de operações com derivativos financeiros visando proteção cambial que, por certo tempo, resultaram também em ganhos de curto prazo, mas que no contexto da crise de 2008 se revelaram catastróficos (BARRETO, 2011; COSTA; SOUSA-SANTOS, 2012). Apesar de a Sadia viver de "vender frango, peru e fazer salsicha" (DIEGUEZ, 2009, p. 2) e de seu CFO (apontado como o responsável pela perda de R $\$ 2,5$ bilhões em 2008) não ser um operador do mercado financeiro, a empresa passou a atuar junto a este espaço por meio de sua controlada, a Concórdia Holding Financeira, formada por um banco, uma corretora e uma gestora de recursos (todos vendidos como exigência para a operação de salvamento empreendida pela concorrente Perdigão, que adquiriu a Sadia e criou a BRF após a crise). Semelhantes perdas (R 2,1 bilhões) também levaram à aquisição da Aracruz pela Votorantim (com a ajuda do BNDES). Segundo Ismail et al. (2011), à época, outras 200 empresas não financeiras enfrentaram dificuldades devido a semelhantes incursões junto à esfera financeira tendo sido necessária a intervenção do BNDES em seus salvamentos.

O emprego de tais práticas denotaria, assim, o empenho de empresas não financeiras em alavancar seus ganhos por meio do mercado de capitais, priorizando junto aos atores externos (ligados às esferas financeiras, como analistas de mercado, investidores institucionais, imprensa

1 Empresa protagonista de um dos maiores escândalos corporativos da história. 
de negócios, gerentes de fundos de investimentos, etc.) narrativas e ações que demonstrem o comprometimento em apresentar um desempenho financeiro atrativo para os investidores, comungando com a lógica de criação de valor ao acionista. É essa concepção de empresa que Fligstein (2005) chamou de "concepção acionária", a eficiência da empresa passa a ser medida em função do valor de suas ações; a mesma passa a ser percebida como um portfólio de ativos, que requer a gestão de sua performance por executivos capazes de garantir o retorno aos investidores, inclusive por meio da venda de ativos cuja rentabilidade esteja abaixo do retorno de investimentos alternativos; e suas relações internas são cada vez mais tratadas como relações de mercado.

Segundo Van der Zwan (2014), a gestão de tais portfólios das empresas sob este signo envolve, além de ações como as tomadas acima pela Sadia e a Aracruz, o pagamento de dividendos crescentes aos acionistas, recompras de ações e o aumento de investimentos em ativos/atividades financeiras, em detrimento de investimentos na esfera produtiva das empresas. Além dessas ações mais explicitamente relacionadas à ascensão da lógica financeira, outras, menos evidentes, têm impactado a organização do trabalho em empresas não financeiras que adotam uma gestão financeirizada (SALTORATO; BENATTI, 2017).

Thompson (2013) observa que, sob a influência da financeirização, houve uma mudança nos mecanismos de controle do trabalho para além dos normativos, sendo os novos desdobrados em função de metas financeiras, gestão de desempenho, disciplina de mercado, externalização do trabalho e inseguridade social. À medida que o processo de financeirização, progressivamente, institucionalizou um novo paradigma para a gestão das grandes empresas de capital aberto, ele acabou por legitimar uma nova percepção acerca do que é empresa e, portanto, sobre como esta deve ser gerida/controlada (SALTORATO; BENATTI, 2018).

Uma vez centrada no aumento do retorno ao acionista, a linguagem financeira se mostrou como aquela capaz de traduzir a lógica financeira, intrínseca à gestão baseada na criação de valor ao acionista (GBV), em um denominador comum que possibilita a comparação/controle entre as diversas divisões/unidades de negócio criadoras/destruidoras de valor (ao acionista) e, portanto, candidatas, respectivamente, a investimentos/desinvestimentos. Considerando ainda a transformação dos relacionamentos organizacionais internos em relações de mercado, acrescenta-se o corolário da remuneração variável como forma de incentivar/controlar o comportamento dos executivos (e demais funcionários), muitas vezes, atrelando tal parcela ao valor das ações da empresa ou ao pagamento de bônus. Diretamente associada à implementação de um sistema de remuneração variável está a gestão/controle do trabalho, por meio do qual metas são definidas, resultados alcançados (ou não) são mensurados e ações corretivas, no caso do não alcance, são empreendidas.

O estudo de caso a seguir explora os mecanismos de controle de uma empresa não financeira, uma credenciadora de cartões de crédito que, até 2012, possuía suas ações negociadas na Bovespa, quando então foi adquirida por uma das maiores instituições financeiras nacionais. 
A lógica da GBV desse conglomerado financeiro, reproduzida discursiva e institucionalmente por meio de inúmeros veículos, levou ao fechamento do capital da recém-adquirida credenciadora e à financeirização de sua gestão, agora, agressivamente voltada para resultados (financeiros).

A proposta metodológica para condução desta pesquisa aplicada, de cunho qualitativo, conjugou uma abordagem teórica, amparada na pesquisa bibliográfica e documental, à uma abordagem empírica que, por meio da aplicação de questionários, realização de entrevistas e da observação participante, em muito contribuiu para a consolidação deste estudo de caso. A pesquisa documental, realizada a partir do exame de procedimentos, relatórios financeiros e pesquisas de satisfação interna, buscou averiguar a criação de valor (ou não) pela credenciadora, por meio da aferição de um dos indicadores emblemáticos da GBV, o Economic Value Added (EVA), aferido antes e depois da aquisição pela instituição financeira. Já a abordagem empírica desta pesquisa combinou a aplicação de questionários junto a 92 Executivos de forma anônima, automatizada e à distância; a condução de 18 entrevistas junto a Executivos (9), Analistas (4) e Coordenadores (5) realizadas presencialmente entre julho e outubro de 2016, na sede da empresa em São Paulo, e; a observante participante de um trabalhador do conglomerado financeiro entre 2011 e 2016; buscando entender como os mecanismos de controle do trabalho implícitos à GBV têm redefinindo a organização do trabalho (OT) na credenciadora.

\section{A organização do trabalho na Credence}

A empresa objeto de estudo de caso, aqui nomeada Credence, é uma credenciadora do segmento de pagamento eletrônico responsável pelo credenciamento, captura, transmissão, processamento e liquidação financeira de transações com cartões de crédito/débito no varejo. Considerando as empresas que atuam junto ao seguimento credenciador da cadeia de pagamentos eletrônicos, tem-se que Cielo, Rede, Getnet, Moderninha, Stone, etc. estão entre os principais players em meio à dinâmica da financeirização do varejo nacional (SALTORATO et al., 2014). As fontes de faturamento da Credence envolvem, principalmente:

- A cobrança de aluguel mensal dos varejistas pelo uso dos terminais POS (Point of Sale), "as maquininhas" que processam os cartões de crédito/débito;

- As taxas cobradas dos varejistas sobre as vendas realizadas (via POS) em função (inversamente proporcional) ao faturamento de cada um deles; ou seja, quanto maior o valor que o varejista se compromete a transacionar via o POS da Credence, menor a taxa estabelecida para o varejista quando do contrato de credenciamento. É comum um mesmo varejista operar com vários POSs simultaneamente, o que implica que ele tenha que continuamente monitorar o volume a ser transacionado em cada POS em função de cada contrato previamente fechado;

- A venda de produtos financeiros; após sua aquisição por uma grande instituição financeira nacional, a Credence passou a disponibilizar aos varejistas a possibilidade de antecipar rece- 
bíveis; ou seja, ao vender a prazo, o varejista pode receber antecipadamente o valor integral da venda, mediante a cobrança de uma taxa proporcional ao valor antecipado. Nesse caso, a instituição financeira ainda assume o risco da inadimplência do consumidor. É importante destacar que antes dessa aquisição, a Credence era essencialmente uma empresa não financeira.

Em 2012, a Credence foi adquirida por uma grande instituição financeira nacional como parte da estratégia de integração vertical da instituição na cadeia de pagamentos eletrônicos no varejo. A partir dessa aquisição, a gestão da Credence passou por uma reformulação, visando incorporar a GBV reproduzida a partir da instituição financeira adquirente. Muitos foram os reflexos dessa incorporação sobre a credenciadora, desde os mais pragmáticos, em meio à adoção de um conjunto de práticas de estratégia/gestão, até os mais simbólicos, fomentando a legitimação de valores organizacionais voltados para a lógica da criação de valor acionista, passando pelos novos mecanismos de organização e controle do trabalhado, foco deste trabalho, e capaz de ilustrar tais reflexos.

\section{O Executivo da Credence: a ressignificação/reinvenção do vendedor}

Um ator a ser destacado em meio à organização do trabalho na Credence é o Executivo, profissional responsável por credenciar (firmar contratos com) varejistas, tornando-os aptos a comercializarem cartões de débito/crédito nas POSs da Credence. Cada Executivo possui metas mensais de credenciamento de varejistas e venda de produtos financeiros. Considerando que os varejistas dispõem de várias opções de POSs (Getnet, Cielo, Rede, Moderninha) para realizar suas vendas, os Executivos têm, dentre outras, a tarefa de fazer com que os varejistas deem preferência ao POS da Credence em suas vendas, visando ao cumprimento de seus contratos em relação ao volume de vendas transacionado. As falas desses profissionais revelam percepções distorcidas sobre suas condições de trabalho:

Então, se [vc] for ver bem, o que acontece? Eles falam que a gente agora virou Executivo e tal e coisa, mas na verdade a gente continua fazendo o que sempre fez; vender, e correr atrás dos caras [os lojistas] prá eles usarem nossa maquininha...o dia todo na rua...É vender, vender, vender, prá depois não passar carão na frente dos outros. (Executivo n ${ }^{\text {o. }}$ 14, São Paulo, Agosto/2016).

Agora, a gente virou Executivo, que é como se fosse um tipo de Consultor. A gente dá assistência para os lojistas, explica que tem que usar nossa maquininha prá ele conseguir mais desconto nas taxas, a gente orienta e acaba fazendo amizade com eles. Eles reclamam prá gente das taxas, a gente escuta, auxilia como pagar menos. Às vezes é meio tenso, muito estresse quando precisamos bater as metas e sabemos que o lojista não tem condição de comprar mais nada da gente. (Executivo $n^{\text {o. }} 19$, São Paulo, Setembro/2016). 
Atualmente, a Credence possui 234 Executivos atuando em São Paulo. A seguir iremos discutir, ponto a ponto, as principais características ligadas à organização do trabalho (OT) desses profissionais.

\section{Autonomia e flexibilidade}

A autonomia e a flexibilidade, centrais à OT na Credence, são pré-requisitos para que o cumprimento das metas possa ser alcançado, não sem intensificação da jornada e sobrecarga de trabalho. Ou seja, os Executivos não são obrigados a comparecer diariamente à estrutura física da Credence, sendo responsáveis por gerir seus horários e suas carteiras de varejistas. Eles são organizados em equipes por região e cada equipe possui um Coordenador responsável por monitorar semanalmente os resultados dos Executivos sob sua responsabilidade, intermediando, quando necessário, a relação entre os mesmos e outra equipe, a do Planejamento Comercial (PC), responsável por definir a carteira (de varejistas) e as metas de cada Executivo.

Um dos mecanismos de controle do trabalho dos Executivos envolve uma plataforma de gestão de visitas. Após cada visita, o Executivo preenche um formulário online, informando os dados relativos ao varejista visitado e os assuntos abordados durante a visita. É de responsabilidade do Coordenador o controle da plataforma pelos Executivos sob seu comando, inclusive checando aleatoriamente a veracidade dos dados inseridos. Segundo um desses Coordenadores:

O controle pode ser feito de forma aleatória prá pegarmos possíveis mentiras; Executivos que dizem que vão em determinado cliente e não vão; Executivos que dizem que ficaram uma hora no estabelecimento e só passaram por lá...Já teve até caso de Executivo forjando credenciamento, só para bater as metas. Às vezes elas são irrealistas mesmo, aí a gente confere, corrige, vai acertando...(Coordenador $\mathrm{n}^{\mathrm{o}}$. 5, São Paulo, Setembro/2016).

\section{Remuneração variável}

A remuneração dos Executivos é outro mecanismo de controle sobre seu trabalho, na medida em que ela é composta majoritariamente por uma parcela variável associada ao alcance das metas definidas pelo Planejamento Comercial (PC). A definição destas metas baseia-se em indicadores de desempenho (de cada Executivo) tornados públicos pela divulgação dos rankings semanais envolvendo estes profissionais. A divulgação de tais rankings também opera como um mecanismo de controle sobre os Executivos que, nesses momentos, têm exposto seus desempenhos perante todos, relatando imensa fonte de pressão e constrangimentos. Essas situações de violência simbólica levam os Executivos a competir entre si, não só por posições no ranking que os livre de tamanho desconforto, como também em função da bonificação monetária destinada aos mais bem posicionados. 
Após a aquisição da Credence pela instituição financeira, a parcela fixa da remuneração decresceu, em prol, advoga o novo proprietário, da possibilidade dos Executivos de aumentar (e muito) seus rendimentos por meio da remuneração variável, sempre que as metas são ultrapassadas. A aferição da remuneração variável por bonificação considera o alcance de metas por duas vias: individual e por equipe. A equipe fará jus à bonificação (por equipe) se $100 \%$ dos Executivos (da equipe) alcançarem suas metas individuais. Ou seja, caso um Executivo não alcance sua meta individual, além de ele não receber sua parcela da remuneração variável individual, a equipe na qual ele está alocado também não fará jus a uma parcela de remuneração variável dita por equipe. Dessa forma, apesar de organizados em equipe, tal arranjo promove somente a competição e a individualização do trabalho dos Executivos (dentro das equipes), e não a realização de trabalho (com espírito) de equipe. Além disso, os resultados das equipes também são publicamente ranqueados, o que implica que a melhor equipe ainda faz jus à outra parcela de remuneração variável, exacerbando ainda mais a pressão sobre os Executivos. Segundo um Executivo:

\begin{abstract}
As metas impostas prá gente, às vezes, a gente nem consegue alcançar, quanto mais, ultrapassar....Então, são poucos os que conseguem os bônus. E além disso, ainda tem $\mathrm{o}$ problema que não adianta nada se você consegue bater sua meta, mas o grupo não bate a meta dele...aí ninguém ganha...E também se o grupo alcança a meta mas um cara da equipe, não alcança, o grupo também perde e ainda fica todo mundo olhando feio prá quem não bateu a meta...É muito injusto, eu acho... (Executivo no. 23, São Paulo, Outubro/2016).
\end{abstract}

Para controlar e avaliar o desempenho dos Executivos da Credence, a OT proposta pela instituição financeira criou uma unidade organizacional destinada exclusivamente a criar/gerir indicadores que pudessem explicitar o impacto do desempenho de cada um (desde o nível operacional até o gerencial) no EVA da empresa, o Departamento de Telecontrole-Intervenção.

\title{
Telecontrole-Intervenção
}

Após a aquisição da credenciadora, o departamento de Telecontrole à época - já vigente na instituição financeira e responsável pela elaboração e acompanhamento de indicadores que focassem no desempenho e performance de todas as empresas do conglomerado - expandiu sua atuação, passando a propor melhorias e acompanhamento destas. Baseado nesse novo escopo, nasceu, dentro da Credence, uma ramificação do Telecontrole, o Telecontrole-Intervenção. Apesar de o termo "Telecontrole" ter sido modificado visando a manter incógnitas tanto a empresa quanto a instituição financeira pesquisada, ele reflete exatamente o termo original, tanto em termos de seu objetivo, o controle do trabalho à distância através do emprego de indicadores quantitativos e qualitativos de desempenho, quanto em termos de certa coincidência fonológica com o termo original. Já o termo "Intervenção" foi mantido tal qual o original visando a ilustrar 
o empenho da instituição financeira no ajuste do comportamento dos Executivos, inclusive por meio da linguagem.

O Telecontrole-Intervenção criado na Credence busca monitorar os indicadores das operações por ele fiscalizadas, identificando padrões, buscando medidas necessárias para reverter maus resultados e acompanhando sua implementação. Em função do alto volume de indicadores monitorados diariamente, o Telecontrole-Intervenção é acionado apenas no caso de reincidência, ou seja, quando um indicador atinge seu ponto crítico mais de uma $\mathrm{vez}^{2}$, e a área responsável não consegue identificar a raiz do problema. Quando o indicador analisado representa um risco de perda significativa para a empresa que não pode ser acionado novamente, o Telecontrole-Intervenção também é acionado. Alguns desses indicadores de risco são relacionados à venda de produtos e serviços, pois eles interferem diretamente no faturamento da instituição financeira e em seu EVA. Sendo assim, no caso dos Executivos, basta que os indicadores de seus desempenhos sejam acionados para que eles entrem em Intervenção. Um dos Executivos que já entrara em Intervenção comentou:

\begin{abstract}
Foi muito ruim....ir para a Intervenção. Atrapalhou até minha vida em casa...Fiquei deprimido, me sentia um vagabundo, apesar de batalhar atrás de lojista o mês inteiro. Tá ruim prá todo mundo.... P PC não vê isso, tem que ver...como quer que a gente venda nessa crise toda? E por causa disso, eu acabei indo pra intervenção, me sentia um lixo, fiquei com muita vergonha...Esse nome também não ajuda né...falei isso pro meu Coordenador. Ele concordou, mas não consegue mudar (Executivo n. 26, São Paulo, Outubro/ 2016).
\end{abstract}

Para monitorar estes indicadores, foi desenvolvido de forma integrada ao TelecontroleIntervenção um modelo de gestão de desempenho, o Modelo Disciplina de Vendas (MDV), a materialização da GBV na Credence.

\title{
Modelo disciplina de vendas ou a GBV em movimento
}

O Modelo Disciplina de Vendas corresponde a um módulo de gestão de desempenho integrado ao Telecontrole-Intervenção que tem como missão, por um lado, identificar e acompanhar segmentos de venda da instituição financeira que não estejam atingindo os resultados de venda projetados e, por outro, operacionalizar a GBV da Instituição financeira junto à Credence. Cada segmento varejista possui um Modelo Disciplina customizado, entretanto, todos seguem um padrão básico antes de incorporar as singularidades de cada segmento, que inclui: a identificação dos indicadores críticos do negócio, a definição do gatilho, a definição do grupo de controle e a intervenção.

2 Os períodos de atualização destes indicadores podem ser realizados diária ou semanalmente, de acordo com a criticidade e a relevância do indicador. 


\section{Identificação dos indicadores críticos}

Nesta etapa, são identificados os indicadores de desempenho que, ao atingir um nível crítico, interferem diretamente no faturamento do segmento. Geralmente estes indicadores estão relacionados à venda de produtos responsáveis por uma parcela significativa do faturamento total do segmento. No caso da Credence, estes indicadores estão relacionados ao volume de credenciamento de varejistas e à venda de produtos como antecipação de recebíveis, sendo eles:

- Visitas: Este indicador revela a média de visitas realizadas pelo Executivo aos varejistas de sua carteira;

- Prospecção: Este indicador mede o valor transacionado pelos POSs dos novos contratos fechados mensalmente;

- Fidelização: Seis meses após fechar um contrato, o Executivo pode renegociar a taxa paga pelo varejista caso ele se comprometa a aumentar o faturamento via aquele POS. Este indicador mede o percentual de aumento de faturamento que o Executivo conseguiu negociar;

- Produtos financeiros: Este indicador mede a quantidade de produtos financeiros vendidos pelo Executivo aos varejistas.

\section{Definição do gatilho}

Após a identificação dos indicadores críticos da operação é definido um gatilho, que caracteriza a métrica de risco do indicador ou o limite, a partir do qual, atingiu-se um nível crítico capaz de acarretar queda de faturamento. Esta definição pode variar considerando a época do ano, decisões do planejamento e mudanças de mercado.

A definição do gatilho dos indicadores da Credence assume como métrica crítica a média de todos os Executivos. Assim, no caso do indicador Visitas, se a média de visitas de todos os Executivos são três visitas por dia, todos os que estiverem abaixo disso são candidatos a entrarem em Intervenção (última etapa do Modelo Disciplina).

\section{Definição do grupo de controle}

Depois da definição do gatilho para cada indicador, realiza-se um estudo considerando o histórico de três meses anteriores para identificar os Executivos que estão abaixo da média em pelo menos um dos indicadores. Dentre as variáveis que podem afetar tal resultado, estão: mudanças do mercado, fatores econômicos e/ou fraco desempenho.

Identificados os Executivos com pior desempenho, verifica-se junto aos coordenadores destes os fatores que podem estar interferindo nos resultados ruins. Esta análise inclui um estudo 
da carteira de cada Executivo visando a entender se as oportunidades de venda estão sendo aproveitadas e se existe um potencial real de incremento de resultado. Depois deste estudo, a meta do Executivo pode ser reavaliada ou o mesmo pode ser encaminhado para a Intervenção.

\section{Intervenção}

Nesta etapa, a primeira atividade é retomar o estudo da carteira do executivo cruzando informações fornecidas pela instituição financeira, visando a rastrear os varejistas que ainda não firmaram contratos, ex-clientes e clientes atuais com potencial de faturamento via POS maior que o realizado. Em seguida, é realizado um benchmarking, isto é, a identificação das técnicas de vendas dos Executivos mais bem ranqueados em cada um dos indicadores críticos, buscando técnicas de negociação e persuasão do varejista para fechar contratos. Após estudar a carteira e tais técnicas, tem início um processo de coaching colocando em ação um plano com os Executivos em Intervenção.

A primeira reunião da Intervenção reúne todos os Executivos nessa situação e seus respectivos coordenadores cuja pauta é explicar a metodologia do Modelo Disciplina, o escopo do Telecontrole-Intervenção e quais indicadores levaram cada Executivo a entrar em Intervenção. Segundo um dos Coordenadores:

É muito desconfortável....Dá dó às vezes...É constrangedor prá gente também...Os Executivos se sentem derrotados e a gente, apesar de estar lá para ajudar, muitas vezes, não consegue e a situação só piora...(Coordenador nº. 20, São Paulo, Setembro/2016).

Após esta reunião, inicia-se um processo de acompanhamento acirrado dos Analistas do Telecontrole-Intervenção sobre os Executivos, por meio de ligações semanais (não rejeitáveis) orientando-os a como melhorar suas carteiras. Nos contatos que se seguem, os Executivos expõem como têm sido suas visitas e as dificuldades para que o Analista possa ajudá-lo a partir das técnicas dos melhores (Executivos). E, caso as orientações não sejam seguidas, o Coordenador (da equipe do Executivo) também passa a ligar endossando as orientações. Esse processo disciplinar da Intervenção perdura até que o gatilho (da métrica) seja ultrapassado, geralmente de dois a três meses. Aqueles que atingem o gatilho, no entanto, continuam sendo monitorados, e os demais seguem controlados até que saiam da Intervenção ou que sejam desligados, período que varia de acordo com o grupo.

Assim, em meio a uma complexa trama de relações de poder, a sujeição, a obediência e o constrangimento disciplinadores assumem contornos e sentidos foucaultianos, esgarçando o tecido social, minando sua força política e operacionalizando o sofisticado projeto de reinvenção dos vendedores enquanto Executivos, empresários ou empreendedores de si mesmos, buscando maximizar seu capital humano, batendo a próxima meta. 


\section{GBV na Credence: financeirização e empresários deles mesmos}

Descritos os mecanismos de controle do trabalho intrínsecos à reprodução da lógica da GBV, comungada pela instituição financeira e suas controladas, realizou-se um levantamento acerca dos indicadores financeiros da empresa entre 2012 (ano de sua aquisição) e 2014, visando a identificar (ou não) a criação de valor ao acionista, mote da GBV, considerando uma das mais importantes métricas que avaliam essa criação de valor, o Economic Value Added (EVA).

\section{Financeirização em números: a criação de valor ao acionista}

Dentre os indicadores (financeiros ou não) que interferem no faturamento e, consequentemente sobre o EVA na Credence tem-se: (i) A evolução do credenciamento; que no período analisado cresceu 639\%; (ii) As antecipações de recebíveis; que entre 2012 e 2014 aumentou 74\%; (iii) A receita; que, em função do crescimento dos outros indicadores, aumentou $34 \%$ entre 2012 e $2014^{3}$. Tomando esses indicadores direcionadores de valor a Tabela 1 ilustra os EVAs calculados a partir dos demonstrativos financeiros publicados pela Credence entre 2011 e 2015:

Tabela 1 - Dados utilizados para o cálculo do EVA (milhares de reais)

\begin{tabular}{|c|c|c|c|c|}
\hline Indicador & 2011 & 2012 & 2013 & 2014 \\
\hline $\begin{array}{l}\text { Lucro Operacional } \\
\text { Antes do Imposto }\end{array}$ & 2.079.397 & 2.438 .908 & 2.877 .508 & 3.998 .629 \\
\hline Patrimônio Líquido & 674.975 & 906.322 & 979.245 & 1.350 .401 \\
\hline $\begin{array}{l}\text { Lucro Operacional Líquido } \\
\text { Após os Impostos }\end{array}$ & 1.404 .422 & 1.618 .586 & 1.898 .263 & 2.648 .228 \\
\hline $\begin{array}{l}\text { Índice Geral de Preços } \\
\text { do Mercado (IGP-M) }\end{array}$ & $5,09 \%$ & $7,81 \%$ & $5,52 \%$ & $3,67 \%$ \\
\hline Patrimônio Líquido & 1.581 .315 & 14.492 .339 & 14.776 .097 & 15.386 .962 \\
\hline EVA & $1.323 .933,07$ & $400.734,32$ & $1.082 .622,45$ & $2.083 .526,50$ \\
\hline
\end{tabular}

Fonte: Elaborado pelos autores a partir de dados internos da empresa.

Observando a Tabela 1, percebe-se que, em 2012, logo após a aquisição da Credence, seu EVA sofreu uma queda de $70 \%$ em relação a 2011, apesar do crescimento do lucro. Tal queda pode ser explicada pelo volume de capital investido na empresa (que para o cálculo do EVA,

3 Apesar do aumento de $13 \%$ dos custos operacionais em 2013, o crescimento da receita, proporcionalmente maior, resultou no aumento do lucro de 30\% (em 2013) e de 50\% no acumulado a partir de 2012. 
no âmbito da GBV, representa um custo), levando seu patrimônio líquido a saltar de R \$ 674 milhões para R\$ 906 milhões. Logo após sua aquisição, a empresa teve seu capital fechado pela instituição financeira que a adquiriu, o que não impediu que uma GBV fosse ali implementada, resultando, em 2014, em um aumento de 57\% do EVA comparado com 2011.

Os documentos internos da empresa, relativos ao segmento varejista assistido pelos Executivos, também indicam resultados positivos, tendo a contribuição do varejo passado de $74 \%$ para $81 \%$ do faturamento total da empresa e saltado de 296 milhões para 1,6 bilhões no EVA do segmento.

A lógica financeira (ou a lógica da criação de valor ao acionista) busca substituir o objetivo de maximização do lucro pelo de maximização do retorno ao acionista, uma vez que a criação de valor transcende o objetivo tradicional da busca do lucro (ASSAF NETO, 2012).

Nesse contexto, o emprego das métricas criadas pelas consultorias (como os EVAs, MVAs, CFROI, etc.) possibilita identificar a contribuição de cada divisão para os resultados finais da empresa e, esta possibilidade de comparação/controle entre unidades organizacionais e/ou indivíduos, por sua vez, acaba por aproximar os relacionamentos organizacionais internos a relações de mercado, levando as divisões internas (e os funcionários) a competirem entre si. Em função disso, a intensificação do monitoramento do desempenho e do controle do trabalho sobre os funcionários da Credence tem recebido severas críticas dos envolvidos.

\section{Financeirização em narrativas: a criação (e intervenção) do Executivo dele mesmo}

De mãos dadas (atadas, na verdade) à legitimação dos resultados financeiros (números) decorrentes da lógica de criação de valor ao acionista, a instituição financeira adquirente promoveu a construção de uma narrativa envolvendo o batismo de seus vendedores enquanto Executivos, profissionais agrupados em equipes com destacada autonomia, flexibilidade e remuneração variável, emblemáticos na institucionalização da GBV na Credence.

Ao promover tal narrativa, a empresa, por um lado, induziu esses profissionais a incorporarem atributos comportamentais idealizados acerca dos chamados homens de negócios, como: ousadia, intrepidez, arrojo, destemor a riscos, espírito empreendedor, ambição, etc. Por outro lado, estes profissionais, dos quais não se exige o ensino superior completo, se veem massacrados por condições precárias de trabalho que incluem, dentre outros, a ausência de vinculação trabalhista via CLT e a contratação dos vendedores como Pessoas Jurídicas, denominada de pejotização. Assim, este ator, diante da ambiguidade de acumular sobre um mesmo corpo (exausto), um patrão e um empregado, forja um empresário de si mesmo, que amalgamando concepções otimistas sobre sua carreira passa a se autogerir e controlar como se capital humano detivesse, ajustando sua postura (inclusive, linguagem e indumentária) segundo sua percepção acerca de como vir a ser um ativo atrativo para o mercado. Porém, tais expectativas, no curso das medições (e exposições) de desempenho diárias, rapidamente 
desbotam-se em meio a constrangimentos e violências simbólicas cuja culpabilidade, no caso de fracassos, é absorvida pelos mesmos.

Ao fim de cada ciclo do Modelo Disciplina, os Executivos respondem a uma pesquisa de satisfação sobre a metodologia deste processo de controle do trabalho. Em 2015, os resultados da pesquisa com 92 Executivos (39\% do total de executivos da Credence) revelaram:

Tabela 2 - Pesquisa de satisfaçao interna

\begin{tabular}{lcc}
\hline Questão & Sim & Não \\
\hline $\begin{array}{l}\text { Você acredita que o Modelo Disciplina é relevante e atende às necessidades } \\
\text { da equipe comercial da Credence? }\end{array}$ & $62 \%$ & $38 \%$ \\
$\begin{array}{l}\text { As orientações dadas pelos analistas durante os contatos foram relevantes? } \\
\begin{array}{l}\text { A escolha dos clientes apontados na sua carteira após análise do Telecontrole } \\
\text { como clientes com potencial de venda foram corretos? }\end{array}\end{array}$ & $53 \%$ & $47 \%$ \\
$\begin{array}{l}\text { Quanto aos indicadores de desempenho, você acredita que o acompanhamento diário } \\
\text { apoia de maneira relevante a sua estratégia de atuação e penetração na carteira de clientes? }\end{array}$ & $33 \%$ & $27 \%$ \\
$\begin{array}{l}\text { A publicação semanal dos indicadores e remuneração variada baseada neles } \\
\text { incentivam o atingimento de suas metas? }\end{array}$ & $67 \%$ \\
\hline
\end{tabular}

Fonte: Dados internos da empresa.

A pesquisa ainda disponibilizou espaço para exposição anonimamente de sugestões e críticas:

Devido ao alto volume de clientes da minha carteira, é difícil gerenciar todos os indicadores ao mesmo tempo e ainda ser assertivo na escolha dos clientes que irei visitar. Neste aspecto a ajuda da Intervenção é bem-vinda, pois é um braço a mais para me ajudar a administrar as visitas e a escolher qual produto devo oferecer para cada cliente e assim atingir minha meta em todos os indicadores (Executivo $\mathrm{n}^{\mathrm{o} .} 19$ ).

As orientações passadas pela Intervenção são válidas, porém eu sugiro tanto o Planejamento Comercial como o Telecontrole a acompanhar a nossa rotina por um dia, e sentir pessoalmente as dificuldades que nós, executivos, enfrentamos para atender às metas, dado um cenário de crise econômica e que afeta diretamente no faturamento de nossos clientes. Acredito que esta experiência poderá tornar mais rica as orientações dadas (Executivo $n^{\circ} \cdot 25$ ).

A exposição dos nossos resultados diariamente e a cobrança do meu coordenador já é pressão suficiente. Muitas vezes preciso deixar de visitar um cliente para atender uma ligação do Telecontrole (Executivo n ${ }^{\text {o. } 32) . ~}$ 
Já os Analistas do Telecontrole-Intervenção da instituição financeira que conduzem o Modelo Disciplina, orientando/telefonando/controlando os Executivos sob Intervenção, foram unânimes quando questionados sobre a eficácia do processo e também ao apontar o maior desafio: convencer o Executivo de que a Intervenção é um apoio e não apenas mais um mecanismo de controle. Segundo eles, o trabalho se torna mais difícil quando o Coordenador também não acredita na metodologia do Modelo Disciplina e não incentiva seu Executivo a seguir as orientações do Telecontrole-Intervenção:

Então, difícil, viu [conduzir o Modelo Disciplina] a gente fica entre a cruz e a espada... porque a gente acredita e já viu que dá resultado, né, mas eles [Executivos e Coordenadores] acham que a gente só tá aqui prá pressionar, então, os cara já vêm com uma resistência muito grande ao processo, que acaba atrapalhando...(Entrevista $\mathrm{n}^{\circ} .8$, Analista, Outubro/2016).

De maneira semelhante aos Executivos, os Coordenadores percebem o TelecontroleIntervenção como alguém dizendo que ele não está fazendo seu trabalho corretamente e que precisa de ajuda externa. Apesar de alguns coordenadores já terem mudado sua opinião ao verem Executivos de sua equipe entrando em Intervenção e depois conseguirem melhorar, no geral, existe bastante resistência por parte destes em relação ao processo. Nas palavras deles:

\begin{abstract}
A Intervenção...bom, já começa pelo nome né, e a gente já falou né...que é muito pejorativo...Ninguém aqui é drogado prá estar em intervenção. Eu considero uma humilhação para o Executivo que tá tentando vender nessa crise danada, e para a gente, que coordena as equipes [de Executivos]. A gente sabe o que está fazendo...se não os resultados não estariam do jeito que vc viu...[se referindo aos resultados financeiros] (Entrevista n ${ }^{\circ}$ 2, Coordenador, Outubro/2016).

Tem muito moleque novo [que atuam fixando as metas do Modelo Disciplina], recém-formado que só sabe mexer em planilha querendo ensinar a gente a vender...Eu acho um desaforo...É fácil ficar em frente à tela, quero ver é gastar sola de sapato debaixo de sol e chuva.... trabalho dos Executivos é muito ingrato e o nosso não é reconhecido (Entrevista $\mathrm{n}^{\mathrm{o}} 4$, Coordenador, Outubro/2016).
\end{abstract}

Os Analistas ressaltam ainda que, assim como os Executivos, eles também têm seu desempenho medido e, quando um executivo em Intervenção não evolui, o analista também é penalizado em sua remuneração e avaliação de desempenho. Segundo um desses Analistas:

A gente não está aqui prá humilhar nem fazer ninguém passar vergonha, mas, às vezes, é essa a sensação que dá....A gente não é carrasco de ninguém, mas eles veem a gente assim e eu acabo me sentindo mal também....Se não tivesse essa resistência, eles [Executivos e Coordenadores] iam ver que a gente tá aqui prá ajudar...E dá certo...Montamos um plano de ação com base nos melhores vendedores...Executivos...e se eles seguirem isso, conseguem sair da Intervenção, já conseguimos recolocar as pessoas... Cê acha que a gente vai fazer um trabalho mal feito...aí a gente não recebe também [a bonificação] (Entrevista n ${ }^{\circ}$ 4, Analista, Outubro/2016). 
Eles também criticam a etapa de definição do grupo de controle pelo Modelo Disciplina, pois muitas vezes a análise da carteira do Executivo conclui que esta está esgotada e que a meta dele precisa ser revista, porém o PC da Credence discorda da análise, insistindo em colocar o Executivo sob Intervenção:

\begin{abstract}
O que tá faltando, na minha opinião, é eles, [Coordenadores e Executivos] entenderem que a gente [Analistas-Coordenadores-Executivos] é um time...A gente tem mais é que se unir, porque a molecada do Modelo Disciplina não perdoa, não tem a experiência que a gente adquiriu. Então fica complicado se a gente aqui embaixo não se une... pior prá gente mesmo. A gente aqui faz a análise considerando um monte de fatores... aí vem os caras [do Modelo Disciplina] e joga o cara em Intervenção. Tá errado isso. (Entrevista, Analista n ${ }^{\circ}$ 3, São Paulo, Novembro/2016).
\end{abstract}

Ao final do ciclo do processo de Intervenção, caso o Executivo não consiga evoluir, todos podem vir a ser penalizados de diferentes formas, sendo a diminuição da remuneração variável a mais comum, conforme a observação participante de um dos pesquisadores. Considerando ainda essa percepção, apesar dos resultados financeiros positivos alcançados pela empresa, as mudanças, para além de agressivas (na OT), se revelaram, violentas, simbolicamente falando e, por isso, são questionadas por muitos, execradas por outros, mas permanecem sendo institucionalizadas pela instituição financeira adquirente.

Dentre os constrangimentos implícitos a tais mudanças, quase que de maneira unânime, os Executivos se referiram à exposição frequente de seus indicadores de desempenho como uma fonte constante de constrangimento, frustração e pressão exercida a partir de todos sobre todos, sejam seus chefes ou seus pares. Este aspecto (dentre outros) da nova abordagem para a OT na credenciadora visava $(\mathrm{m})$ a fomentar a competição entre os Executivos, porém acabaram promovendo uma crescente individualização no ambiente de trabalho, vista pela maioria como desestimulante. Houve, no entanto, quem argumentasse que a nova OT incentivava a busca por resultados:

Eu acho que essa nova fase, esse novo ambiente da empresa é muito bom prá todos porque a gente tem mais flexibilidade...de horário, por exemplo...Prá mim, isso é importante....Mas além disso, agora que somos/viramos Executivos eu também acho que dá prá ganhar mais. Só dependo de mim mesmo prá ter resultados. Eu corro atrás, tô sempre martelando na cabeça do varejista que ele precisa dos nossos produtos, e dá certo...quem faz isso gente ganha mais... (Entrevista n ${ }^{\circ} \cdot 12$, Executivo, Outubro/2016).

Outro aspecto percebido como fonte de constrangimento é a distribuição inversamente proporcional do EVA entre os Executivos e acionistas. Enquanto ao longo dos últimos anos, a distribuição entre os acionistas vem aumentando, entre os Executivos, ela vem diminuindo (Figura 1): 
Figura 1 - Distribuição do EVA

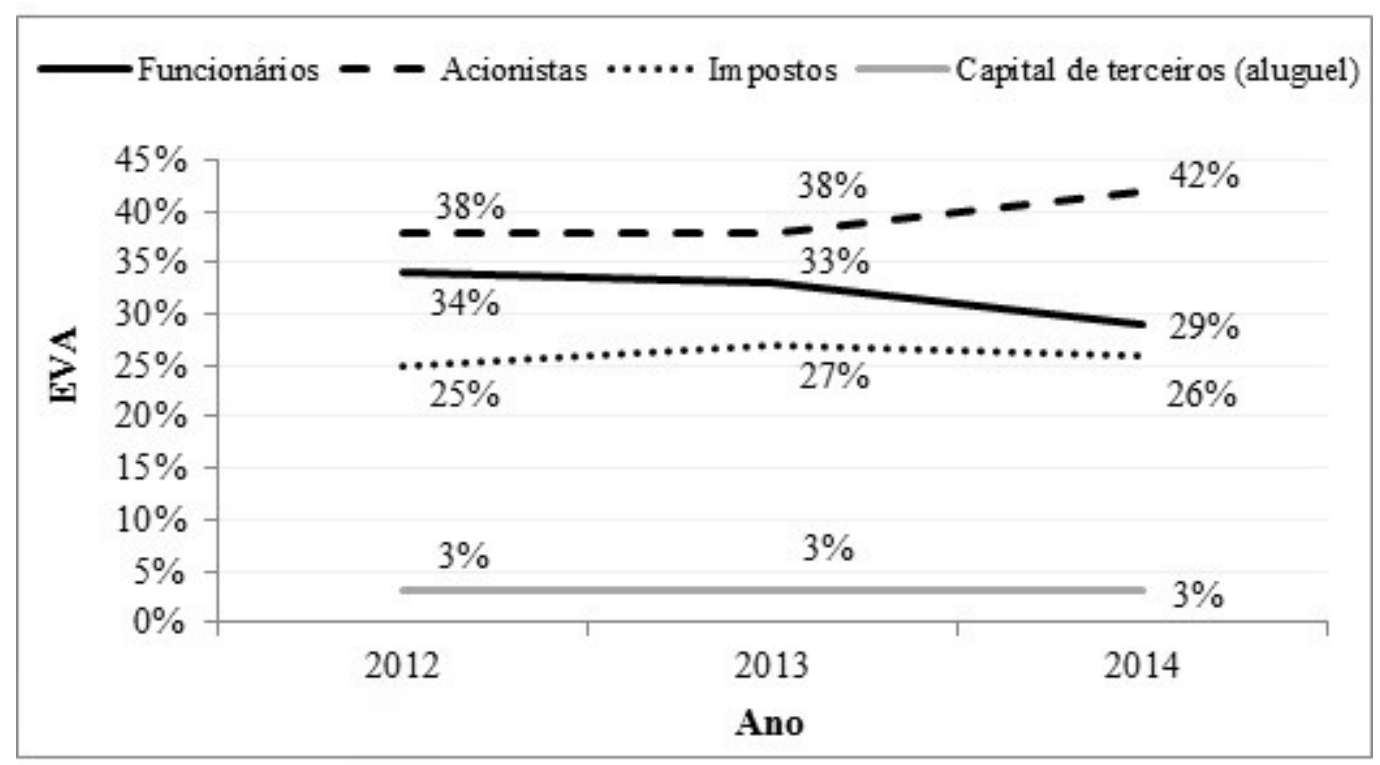

Fonte: Dados internos da empresa.

Diante dos resultados financeiros da empresa, alguns profissionais se sentem orgulhosos do papel que acreditam ter desempenhado para seu alcance, apesar de culparem outros pela falta de iniciativa e ambição:

As metas são altas, concordo...então, também tem que torcer prá não cair nenhum [Executivo] muito fraco na sua equipe, senão...dá raiva, a gente se mata e o cara, nada... aí dá ruim né...

\section{Considerações finais}

O presente trabalho teve como objetivo explorar os mecanismos de controle e de medição de desempenho no âmbito da organização do trabalho de uma credenciadora de cartões de crédito considerando a GBV adotada, após sua aquisição por uma das maiores instituições financeiras nacionais. A GBV, enquanto corolária de um processo mais amplo, a financeirização, encerra um novo modo de conceber e agir sobre empresas que estejam sob a pressão de gerar crescentes retornos aos acionistas. Essas passam a ser percebidas como portfólios de ativos cuja gestão requer o emprego de mecanismos atinentes à lógica da geração de valor, ou seja, que busca, dentre os investimentos disponíveis no mercado, aqueles cuja rentabilidade suplanta o tão somente tradicional lucro.

No entanto, Saltorato e Benatti (2017) destacam que a assimetria de informações entre investidores externos e executivos leva relevantes autores (BOYER, 2005; LAZONICK, 2009; MONTALBAN; SAKINÇ, 2011) a questionarem a capacidade efetiva dos investidores de fazer 
com que os executivos priorizem seus interesses acima dos de outros atores. Porém, ainda segundo os autores, o fato é que as firmas sob este tipo de pressão, tipicamente as empresas de capital aberto (mas não exclusivamente, como mostrou o estudo de caso) se encontram em algum lugar do continuum da atuação desses investidores e, assim, sua presença não pode ser ignorada. E, de fato, os mecanismos associados à gestão agressiva da GBV mostram que tal pressão não está sendo ignorada.

No âmbito simbólico, este estudo de caso explorou a ressignificação do profissional de vendas enquanto um novo Executivo, sujeito a novas fontes de constrangimento e violência simbólica, na medida em que as relações organizacionais internas passam a ser cada vez mais expressas enquanto relações de mercado - considerando as medições, exposições e rankeamentos dos desempenhos individuais desses vendedores e o processo disciplinador das posturas - subjetividades e comportamentos na incorporação de valores, crenças, mitos e ritos, são alinhados com a lógica de mercado, mais especificamente, do mercado financeiro. A lógica financeira imposta à credenciadora adquirida levou a uma reestruturação organizacional, originando o Departamento Telecontrole-Intervenção para telemedir e intervir sobre o desempenho dos Executivos.

Considerando os desempenhos financeiros da empresa (anterior e posteriormente à sua aquisição pela instituição financeira) e os desempenhos individuais dos Executivos, percebe-se que, enquanto a reprodução das práticas/cultura da GBV na empresa contribuiu positivamente para os resultados [financeiros] alcançados, a influência daquelas mesmas [práticas/cultura] sobre a organização do trabalho não foi tão bem percebida. Alguns Executivos apontaram diversas fontes de constrangimento, como: a forte pressão por resultados exercida pelo Planejamento Comercial (PC) e o Telecontrole-Intervenção; a exposição de seus desempenhos individuais junto aos seus pares, sujeitando-os ao escrutínio dos mesmos; a possibilidade de "entrar em intervenção", inclusive, devido a metas mal definidas, inalcançáveis ou não-revistas; a diminuição da parcela fixa de suas remunerações em função da promessa de uma parcela variável crescente (às vezes, dependente do alcance de metas irrealizáveis); o controle social exercido pelos pares da mesma equipe ao se sentirem prejudicados quando do não alcance da meta individual por um Executivo da equipe, resultando em perdas para a meta coletiva por equipe; a falta de incentivos à cooperação entre os Executivos, todos abarrotados com suas metas individuais, sem tempo para cooperar com os demais; a não aferição da meta da equipe de maneira agregada, ou seja, equilibrando os resultados daqueles que alcançaram suas metas com os demais, visando ao alcance da remuneração extra para todos; a ameaça (e a realidade) constante da perda do emprego; fomentando um ambiente de crescente individualização e competição entre os pares.

Além dos Executivos, outros profissionais, nessa nova OT, como os Analistas do Telecontrole-Intervenção, também demonstraram frustração ao terem suas avaliações sobre as metas ignoradas (não revistas) pelo PC, bem como ao verem o descrédito dos Coordenadores 
pelo seu trabalho e a ineficácia da Intervenção sobre alguns Executivos resultar em perdas em suas próprias remunerações. Apesar disso, visivelmente constrangidos no âmbito das entrevistas realizadas no ambiente de trabalho, eles manifestaram que as práticas da GBV são positivas e não um mero mecanismo de controle.

Os Coordenadores, por sua vez, demonstraram falta de confiança na metodologia, contrariedade ao submeter seus subordinados à Intervenção e pouca inclinação para acompanhar o processo.

$\mathrm{Na}$ empresa pesquisada (em todas as demais pertencentes a holding da instituição financeira e empresas que atuam sob o signo da GBV, de forma geral), o EVA se desdobra em indicadores direcionadores de valor para os níveis operacionais, visando compartilhar a responsabilidade da criação de valor com todos, intensificar a aferição do desempenho individual e diminuir a dispersão do resultado individual entre a equipe. Ou seja, o objetivo do agrupamento dos Executivos em equipes, a priori percebido como um mecanismo para fomentar a coesão interequipe (tendo em vista sua bonificação) e a competição intraequipes, acabou por apenas exacerbar a competição dentro da equipe, constrangendo (e desmotivando) alguns e segregando todos; contrariando, assim, a pressuposição dos economistas financistas, atores centrais na institucionalização da financeirização (SALTORATO; BENATTI, 2018), de que a remuneração variável estimularia o trabalhador a agir como dono do negócio, mobilizando-o em torno da causa da criação de valor.

Segundo Donadone et al. (2010, p. 18), "no mercado de ideias sobre organizações, e mais genericamente sobre a interpretação do mundo atual, a ideia de financeirização concorre com a da sociedade em rede". Segundo os autores, enquanto a ideia de financeirização encerra as interpretações pessimistas sobre organização do trabalho, com destaque para a intensificação de seu controle e de sua precarização, a da sociedade em rede incorpora uma versão mais otimista, segundo a qual a sociedade atual estaria buscando a superação das formas burocráticas ultrapassadas que impõem barreiras à criatividade, conectividade, flexibilidade e, de maneira geral, ao autodesenvolvimento (DONADONE et al., 2010).

No estudo de caso apresentado, a autonomia e a flexibilidade presentes no trabalho dos executivos na Credence trouxeram consigo intensificação da carga e do controle do trabalho e autonomia/flexibilidade para gerir suas carteiras. A flexibilidade imposta ao trabalho do Executivo acabou por superar tão somente a burocracia/proteção inerente ao vínculo trabalhista, uma vez que alguns passaram a optar por serem contratados como pessoas jurídicas (PJ), talvez em função do ligeiro aumento na parcela fixa do salário.

Assim, a flexibilidade e autonomia conquistadas, embora não tenham derrubado as barreiras da criatividade (ou do autodesenvolvimento), certamente deitaram a do limite da jornada de trabalho, agora à mercê do funcionamento varejista, sendo as visitas (um dos mais importantes indicadores de desempenho) realizadas aos sábados, domingos, feriados ou qualquer outro horário não comercial. Neste sentido, apesar de o discurso da flexibilidade aludir à relativização 
dos mecanismos de controle, o oposto disso foi observado no estudo de caso, antagonizando com a "promessa instigante de inserção na sociedade em rede" (GRÜN, 2003, p. 5).

\section{Referências}

ANDERSSON, T et al. Financialization directing strategy. Accounting Forum, v. 32, n. 4, p. 261-275, 2008.

ARRIGHI, G. The Long Twentieth Century: money, power, and the origins of our times. London: Verso, 1994.

ASSAF NETO, A. Instituto Assaf. 2012. Disponível em: http://www.institutoassaf.com.br/2012/. Acesso em: 20 out. 2018.

BARRETO, R. G. Operações de hedge cambial em empresas não-financeiras: um estudo de caso das empresas Aracruz celulose e Sadia. 2011. Dissertação (Mestrado em Gestão Empresarial) - Escola Brasileira de Administração Pública e de Empresas, Fundação Getúlio Vargas, Rio de Janeiro, 2011.

BOYER, R. From Shareholder Power to CEO Power. The paradox of 90s. Competition \& Change, v. 9, n. 1, p. 7-47, 2005.

BRAGA, J.C.S. Financeirização global: o padrão sistêmico de riqueza do capitalismo contemporâneo. In: TAVARES, M.C.; FIORI, J.L. (org.). Poder e dinheiro: uma economia política da globalização. Petrópolis: Vozes, 1997. p. 195-242.

CHESNAIS, F. O capital portador de juros: acumulação, internacionalização, efeitos econômicos e políticos. In: CHESNAIS, F. (org.) A finança mundializada. São Paulo: Boitempo, 2005. p. 35-67.

COOPER, D. J.; EZZAMEL, M. Globalization discourses and performance measurement systems in a multinational firm. Accounting, Organizations and Society, v. 38, n. 4, p. 288-313, 2013.

COSTA, A. D.; SOUSA-SANTOS, E.R. Financeirização e reestruturação produtiva: evidências pós-crise financeira de 2008. Revista Economia \& Tecnologia, Curitiba, v. 8, n. 1, p. 35-46, 2012.

DAVIS, G. F. Managed by the Markets: How Finance Re-Shaped America. London: Oxford University Press, 2009. DIAS, A.V.; ZILBOVICIUS M. A produção face à financeirização: quais consequências para a organização da produção e do trabalho? Uma proposta de agenda de pesquisa para a engenharia de produção brasileira. In: ENCONTRO NACIONAL DE ENGENHARIA DE PRODUÇÃO, 26., 2006, Fortaleza. Anais do XXVI Encontro Nacional de Engenharia de Produção. Fortaleza, 2006.

DIEGUEZ, C. O setembro negro da Sadia. Anais da vida empresarial. 2009. Disponível em: http://piaui.folha.uol. com.br/materia/o-setembro-negro-da-sadia/. Acesso em: 20 set. 2018.

DONADONE, J. et al. Centralidade e fronteiras da empresa e as novas formas de atuação e configuração da Engenharia de Produção. In: OLIVEIRA, V.; CAVENAGHI, V.; MÁSCULO, F. (org.). Tópicos emergentes e desafios metodológicos em engenharia de produção: casos, experiências e proposições. Rio de Janeiro: ABEPRO, 2010. p.15-86.

EPSTEIN, G. A. Financialization and the World Economy. Cheltenham: Edward Elgar, 2005.

ERTURK, I. et al. The democratization of finance? Promises, outcomes and conditions. Review of International Political Economy, v. 14, n. 4, p. 553-575, 2007.

ERTURK, I. et al. Corporate governance and impossibilism. Journal of Cultural Economy, v. 1, n. 2, p. 109-127, 2008.n

EZZAMEL, M.; WILLMOTT, H.; WORTHINGTON, F. Manufacturing shareholder value: The role of accounting in organizational transformation. Accounting, Organizations and Society, v. 33, n. 2, p. 107-140, 2008. 
FANTTI, M. B. Financeirização da produção e as consequências para a organização do trabalho. In: ENCONTRO NACIONAL DE ENGENHARIA DE PRODUÇÃO, 33., 2013, Salvador. Anais do XXXIII Encontro Nacional de Engenharia de Produção, Salvador, 2013.

FLIGSTEIN, N. The End of (Shareholder Value) Ideology? Political Power and Social Theory, v. 17, p. 223-233, 2005.

FLIGSTEIN, N. The Transformation of Corporate Control. Cambridge: Harvard University Press, 1990.

FOUCAULT, M. Vigiar e punir: nascimento da prisão. Petrópolis: Vozes, 2015.

FROUD, J. et al. Shareholder value and financialization: consultancy promises, management moves. Economy and Society, v. 29, n. 1, p. 80-110, 2000.

FROUD, J. et al. Financialization and Strategy. New York: Routledge, 2006.

FROUD, J. et al. General Electric: The Conditions of Success. In: FROUD, J. et al. Financialization and Strategy. New York: Routledge, 2005.

GRÜN, R. Modelos de Mundo, Modelos de Empresa: Sobre Algumas Características Culturais da Nova Ordem Econômica e da Resistência a Ela. Revista Brasileira de Ciências Sociais, São Paulo, v. 14, n. 41, p. 121-140, 1999. GRÜN, R. Atores e Ações na Construção da Governança Corporativa Brasileira. Revista Brasileira de Ciências Sociais, São Paulo, v. 18, n. 52, p. 139-162, 2003.

ISMAIL, R. et al. Entrevista com Luciano Coutinho. Cadernos do Desenvolvimento, Rio de Janeiro, v. 6, n. 9, p. 406-419, 2011.

LAZONICK, W. Sustainable Prosperity in the New Economy? Business Organization and High-Tech Employment in the United States. Michigan: Upjohn Institute for Employment Research, 2009.

LAZONICK, W.; O'SULLIVAN, M. Maximizing Shareholder Value: A New Ideology for Corporate Governance. Economy and Society, v. 29, p. 13-35, 2000.

LEE, E.; YIN, Y. P. Off-shoring and out-sourcing for shareholder value: Promises versus reality. Accounting Forum, v. 36, p. 18-26, 2012.

MATSUDA, P. M.; DONADONE, J. C. A mudança da carreira dos dirigentes após o processo de privatização: estudo de caso no setor elétrico paulista. Gestão \& Produção, São Carlos, v. 22, n. 2, p. 419-430, 2015.

MONTALBAN, M.; SAKINÇ, M. E. How financialization shapes productive models in pharmaceutical industry: the domination and contradictions of the blockbuster productive model. Groupe de Recherche en Economie Théorique et Appliquée - FINNOV Discussion Paper, p. 1-35, 2011.

MONTGOMERIE, J. The Financialization of the American Credit Card Industry. Competition \& Change, v. 10, n. 3, p. 301-319, 2006.

MORAES, L. C. G. Nas Asas do Capital: Embraer, Financeirização e Implicações sobre os Trabalhadores. Caderno CRH, Salvador, v. 30, n. 79, 2017.

MUELLERLEILE, C. Financialization takess off at Boeing. Journal of Economic Geography, v. 9, n. 5, p. 663-677, 2009.

MUNDO NETO, M. A lógica financeira e o espaço do transporte aéreo comercial Brasileiro. Gestão \& Produção, São Carlos, v. 18, n. 2, p. 311-324, 2011.

POWELL, W. W. The Capitalist Firm in the Twenty-First Century: Emerging Patterns in Western Enterprise. In: DIMAgGIO, P. (org.). The Twenty-First Century Firm: Changing Economic Organization in International Perspective. Princeton: Princeton University Press, 2001. p. 33-68.

RACHID, A.; RICCI, M. G.; SALTORATO, P. O controle do trabalho em um call center de cobrança. Política \& Trabalho - Revista de Ciências Sociais, João Pessoa, n. 46, p. 181-199, 2017. 
SALTORATO, P.; BENATTI, G. O Ato Performático da Reestruturação Organizacional sob a Ideologia da Gestão Baseada em Valor. Revista Brasileira de Gestão de Negócios, São Paulo, v. 19, n. 64, p. 263-288, 2017.

SALTORATO, P.; BENATTI, G. Reinventando o Management: Da Construção Social do Shareholder Value à Emergência do CEO Celebridade. Gestão \& Produção, São Carlos, v. 25, n. 2, p. 251-268, 2018.

SALTORATO, P. et al. From stores to banks: the financialization of the retail trade in Brazil. Latin American Perspectives, v. 41, n. 5, p. 110-128, 2014.

SHEPPARD, D.; HUME, N. A Prison ID in one hand - and a CFO Award in the other. 2015. Financial Times, Londres. Disponível em: https://www.ft.com/content/8ffd2c8a-201e-11e5-ab0f-6bb9974f25d0 Acesso em: 15 set. 2017. THOMPSON, P. Financialization and the Workplace: Extending and Applying the Disonnected Capitalism Thesis. Work, Employment and Society, v. 27, n. 3, p. 472-488, 2013.

USEEM, M. Executive Defense: Shareholder Power and Corporate Reorganization. Cambridge: Harvard University Press, 1993.

VAN DER ZWAN, N. Making sense of financialization. Socio-Economic Review, v. 12, n. 1, p. 99-129, 2014.

WIDMER, F. Institutional investors, corporate elites and the building of a market for corporate control. Socio-Economic Review, v. 9, n. 4, p. 671-697, 2011.

Recebido em: 06/09/2019

Aceito em: 28/10/2019 